\title{
UMA POSSÍVEL DEFINIÇÃO DO ROMANCE DE FORMAÇÃO COMO CATEGORIA AUTOBIOGRÁFICA
}

\author{
Luiz Henrique Ernesto Coelho ${ }^{1}$
}

\begin{abstract}
Resumo: No texto "Bekenntnisse einer schönen Seele", inscrito no romance Wilhelm Meisters Lehrjahre, Goethe descreve a formação de uma personagem feminina, baseando-se nos escritos de Susanna von Klettenberg, prima e amiga de sua mãe. A presente investigação busca problematizar as categorias definidoras da autobiografia, biografia e ficção apresentadas pelos autores Philippe Lejeune, Leonor Arfuch, Tununa Mercado, entre outros, a partir de suas possíveis abrangências para o gênero do romance. Para tanto, o texto supracitado será analisado como modelo, o qual se encontra em um topos limítrofe entre ficção, biografia e autobiografia.
\end{abstract}

Palavras-Chave: J.W. Goethe; Philippe Lejeune; Leonor Arfuch; Autobiografia.

Abstract: In the text "Bekenntnisse einer schönen Seele" inscribed in the novel Wilhelm Meisters Lehrjahre, Goethe depicts a feminine character's formation, based on Susanna von Klettenberg's notes, his mother's cousin and friend. The present investigation intends to problematize the defining categories of autobiograpy and fiction, presented by the authors Philippe Lejeune, Leonor Arfuch, Tununa Mercado among others, from their possible coverages for the roman genre. Therefore, the aforementioned text will be analysed as a model, which can be found in a bordering topos between fiction biography and autobiography.

Keywords: J. W. Goethe; Philippe Lejeune; Leonor Arfuch; Autobiography.

\footnotetext{
${ }^{1}$ Mestrando em Teoria da Literatura e Literatura Comparada junto ao Programa de PósGraduação em Estudos Literários (Póslit), da Faculdade de Letras da UFMG - Universidade Federal de Minas Gerais; desenvolve pesquisa no âmbito da Literatura Alemã. E-mail: coelho.luizhenrique@gmail.com.

${ }^{2}$ [Confissões de uma bela alma] trad. Nicolino Simone Neto.
} 


\section{Philippe Lejeune e o pacto autobiográfico}

Em seu texto "O pacto autobiográfico", Philippe Lejeune propõe uma divisão entre categorias dos gêneros que possivelmente se inscrevem em uma definição de autobiografia. Para tanto, o autor inclui outras denominações, como, por exemplo, a biografia e também o romance autobiográfico. Em todos eles o elemento em comum é a narrativa remetendo a eventos que descrevem o autor. Segundo Lejeune,

[d]e fato, ao colocar o problema do autor, a autobiografia elucida fenômenos que a ficção deixa numa zona de indecisão: em particular o fato de que pode muito bem haver identidade do narrador e do personagem principal no caso da narrativa "em terceira pessoa". Essa identidade, embora não seja mais estabelecida no texto pelo emprego do "eu", é estabelecida indiretamente, mas sem nenhuma ambiguidade, através da dupla equação: autor = personagem, donde se deduz que narrador $=$ personagem, mesmo se 0 narrador permanecer implícito. Este procedimento correspondente, ao pé da letra, ao sentido primeiro da palavra autobiografia: é uma biografia, escrita pelo interessado, mas escrita como uma simples biografia. (LEJEUNE, 2014, p. 19)

Para o autor, a autobiografia é marcada, na maior parte das vezes, pela escrita em primeira pessoa, dada pela identidade do narrador-personagem principal. (2014, p. 18) Esta característica, advertida e denominada por Gérard Genette como narração "autodiegética”, é estabelecida a partir de obras de ficção ${ }^{3}$. Contudo, Genette afirma também que "é possível haver narrativa em 'primeira pessoa' sem que o personagem seja a mesma pessoa que o personagem principal". O autor denomina esta variante de narração "homodiegética", na qual percebe-se a possibilidade de uma identidade do narrador e o personagem principal sem o uso de uma narração em primeira pessoa (2014, p. 18). Nesse caso, o narrador cria uma ideia de orgulho por sua identidade relacionada ao personagem ou uma noção de humildade associada a este. Lejeune exemplifica esses casos, dados pelas cartas do

\footnotetext{
${ }^{3}$ GENETTE, Gérard. Figures III. Paris: Seuil, 1972 apud LEJEUNE, 2014, p. 18.
} 
imperador romano César ou pelas do ex-presidente francês, Charles de Gaulle, por um lado, e por outro, a autodenominação "servo de Deus" faz referência à identidade do narrador se referindo ao personagem humilde, mencionado por Lejeune (2014, p. 18). Em todos os casos, está presente a identidade do narrador como o personagem principal, o que define a escrita autobiográfica, inicialmente. Existem ainda, casos em que toda a descrição do personagem se dá em terceira pessoa e, em todo o restante, a voz narrativa se confunde com o personagem principal. Esta última instância é frequentemente encontrada em alguns gêneros ficcionais, tais como 0 Romance de Formação, principalmente em sua gênese conceitual, no século $\mathrm{XVIII.}^{4}$

Nos casos de uma escrita ficcional, Lejeune procura diferenciar os elementos que remetem diretamente a uma escrita autobiográfica daqueles que estão relacionados, por exemplo, ao que ele determina como sendo um romance autobiográfico. Tais textos parecem ao leitor não serem ficcionais e exprimem essa impressão por trazerem em suas narrativas, comparações com outros textos, informações externas, inseridas, por exemplo, com descrições fidedignas de ambientes reais, ou pela narrativa que incorre em algum fator que denota verossimilhança, sendo, contudo, ficcional: "[...] (como quando alguém diz: 'Eu tinha um grande amigo a quem aconteceu...' e começa a contar a história desse amigo com conviç̧ão inteiramente pessoal)" (LEJEUNE, 2014, p. 29).

[...] o romance autobiográfico engloba tanto narrativas em primeira pessoa (identidade do narrador e do personagem) quanto narrativas "impessoais" (personagens designados em terceira pessoa); ele se define por seu conteúdo. À diferença da autobiografia, ele comporta graus. A semelhança suposta

\footnotetext{
${ }^{4}$ Aqui faz-se importante mencionar o uso da autobiografia nos protótipos de Romances de Formação alemães do século XVIII. Segundo Jürgen Jacobs, em seu texto "Vorbereitung des Bildungsromans in deutschen Autobiographien und Romanen des 18. Jahrhunderts", tem-se frisado que as autobiografias pietistas tiveram um papel importante nos protótipos do Romance de Formação. Isso é sem dúvida, possível, desde que atenha-se à habilidade de classificações diferenciadas de processos morais e ao encontro consciente com as conseguintes características pessoais do desenvolvimento da vida [do autor-narrador]" (JACOBS, 1972, p. 39; Tradução minha).
} 
pelo leitor pode variar de um vago "ar de família" entre o personagem e o autor até uma quase transparência que leva a dizer que aquele é o autor "cuspido e escarrado". Assim, a respeito de L'anné du crabe [O ano do caranguejo] 1972, de Oliver Todd, um crítico escreveu que "o livro inteiro se confessa obsessivamente autobiográfico por detrás dos pseudônimos transparentes". 5 Já a autobiografia não comporta graus: é tudo ou nada. (2014, p. 29)

Após estabelecido o "contrato" entre autor e leitor, a tendência deste, para Lejeune, seria encontrar justamente aquilo que difere uma autobiografia da escrita ficcional ou, mais precisamente, do romance autobiográfico. Sua recepção estaria ligada a uma vontade de encontrar os erros e inverdades, os quais fariam de uma narrativa, um texto ficcional. Assim, uma definição de autobiografia estaria ligada à ideia de fidelidade ou, em uma última instância, ao nome próprio apresentado como a identidade entre o autor e o personagem principal, sendo esta relação intermediada pelo narrador, como mencionado acima (2014, p. 31). Essa identidade pode ser estabelecida de duas maneiras: implicitamente, definida no momento do "pacto autobiográfico" (2014, p. 31), que pode fazer uso de títulos que confirmem a relação entre as três partes. Ex.: "História de minha vida"; Na seção inicial do texto, onde o narrador compromete-se, junto ao leitor, ao se comportar como autor, retirando qualquer dúvida do leitor de que o "eu" - pronome usado durante a narrativa - remeta ao nome escrito na capa do livro (2014, p. 32).

Lejeune expõe, o que chama de "llusão", a ideia de que o romance possa conferir mais autenticidade do que a autobiografia propriamente dita. Para ele, esse é um lugar-comum, e "como todo lugar-comum, foram-lhes emprestadas várias vozes” (2014, p. 49). Dentre os autores que defendem essa possibilidade, André Gide, em seu texto Si le grain ne meurt afirma: "As memórias só são mais sinceras pela metade, por maior que seja a preocupação com a verdade: tudo é sempre mais complicado do que dizemos. Talvez se chegue mesmo mais perto da verdade no romance" Ainda no intuito de combater esse lugar-comum, é mencionado, também,

\footnotetext{
${ }^{5}$ POIROT-DELPECH, Bertrand. Le Monde, 13 out. 1972 apud LEJEUNE, 2014, p. 29.

${ }^{6}$ GIDE, André. Si le grain ne meurt. Paris: Gallimard, 1972. p. 278 apud LEJEUNE, 2014, p. 49).
} 
Albert Thibaudet, que deu à defesa do romance - ou do lugar-comum, como proposto acima - "a forma acadêmica do 'paralelo', tema ideal de dissertações, contrapondo o romance (profundo e múltiplo) à autobiografia (superficial e esquemática)"7. Para Lejeune,

[...] o leitor frequentemente esquece que, nesses dois julgamentos, a autobiografia aparece em dois níveis: ela é, ao mesmo tempo, um dos termos da comparação e o critério que serve de comparação. Qual seria essa verdade da qual o romance permite chegar mais perto, senão a verdade pessoal, individual íntima, do autor, isto é, aquilo que todo projeto autobiográfico visa? Por assim dizer, é enquanto autobiografia que se decretou ser o romance mais verdadeiro.

O leitor é assim convidado a ler os romances não apenas como ficções remetendo a uma verdade da 'natureza humana', mas também como fantasmas reveladores de um indivíduo. Denominarei essa forma direta de pacto autobiográfico de pacto fantasmático. (LEJEUNE, 2014, p. 50)

Para o autor, a cisão entre a autobiografia o romance não estaria, então, relacionada as suas particularidades, que os diferenciariam entre si, mas ligada ao contrato estabelecido com o leitor e definido a partir de sua percepção, no texto, dos elementos que definem cada gênero (2014, p. 50).

\section{O narrador - Walter Benjamin}

Ao tratar da figura do narrador e também da relação entre narrativa e informação, Walter Benjamin explica dois pontos importantes a esta pesquisa. Um que refere-se diretamente à relação entre informação e narrativa, e o outro, tocante ao Romance de Formação e sua relação com a realidade e ficção.

A informação, um dos adventos do mundo moderno, estaria segundo Benjamin diretamente relacionada ao declínio da narrativa, mais precisamente

\footnotetext{
${ }^{7}$ THIBAUDET, Albert. Gustave Flaubert. Paris: Gallimard, 1935, pp. 87-88 apud LEJEUNE, 2014, p. 49.
} 
da narrativa oral. A informação se relaciona com o imediatismo comunicativo proposto por essa época, e prescinde de verificação, do mesmo modo, imediata. Segundo o autor, ela "precisa ser compreensível 'em si e para si". Este componente relaciona-se com a invenção da imprensa, que possibilita tal dinamismo. Em oposição a isso, estaria a narrativa, que remete ao relato dos antigos e possivelmente, segundo Benjamin, seria mais precisa que a informação, mesmo que nela sejam encontrados aspectos ficcionais (BENJAMIN, 1983, p. 203).

Para o autor, a chegada da imprensa, que possibilita no início do mundo moderno o surgimento do livro, e, trazendo, por consequência, a difusão do romance, são fatores que acarretam no declínio da narrativa oral e assim, da epopeia (BENJAMIN, 1983, p. 201). Para ele,

[a] origem do romance é o indivíduo isolado, que não pode mais falar exemplarmente sobre suas preocupações mais importantes e que não recebe conselhos nem sabe dá-los. Escrever um romance significa, na descrição de uma vida humana, levar o incomensurável a seus últimos limites. Na riqueza dessa vida e na descrição dessa riqueza, o romance anuncia a profunda perplexidade de quem a vive. (1983, p. 201)

Aqui, Benjamin demonstra, primeiramente, a sua preocupação com 0 que seria o autor do romance, que exemplifica o indivíduo moderno, e, posteriormente, a relação tão próxima entre a biografia e a escrita ficcional, representada pela forma do romance. Para o autor, com o passar do tempo, existiram tentativas de se agregar conhecimento ao gênero. O Romance de Formação seria, segundo o seu ponto de vista, "[...] o melhor exemplo, talvez seja o Wilhelm Meisters Lehrjahre (Os anos de aprendizado de Wilhelm Meister) -, essas tentativas resultaram sempre na transformação da própria forma romanesca" (BENJAMIN, 1983, pp. 201-202). A partir da análise benjaminiana, percebe-se o propósito dos autores de romance - desde suas primeiras acepções até o Romance de Formação - de relatar, mesmo que recorrendo à ficção, aquilo que pertencia as suas vidas. Este intento seria, nas 
palavras, de Leonor Arfuch, algo que simbolizaria a escrita romanesca do século 18 e, sobretudo, de Goethe.

\section{Leonor Arfuch e uma releitura (ou atualização) das formas de autobiografia}

No texto "O espaço biográfico na (re)configuração da subjetividade contemporânea", a autora Leonor Arfuch expande os limites propostos por Lejeune para uma definição da autobiografia. Essa leitura traz novos caminhos para o gênero baseando-se nas experiências, sobretudo, contemporâneas e, nas palavras da autora, "midiáticas". Assim, a autobiografia deixa de ser apenas um gênero literário e passar a agregar outras experiências que redefinem o "eu" autobiográfico.

Mas como definir hoje essa palavra, que há muito abandonou seus limites canônicos, sua 'terra natal', a escrita, para esfumar-se na oralidade, nas telas, na reverberação sem fim da cultura da imagem? como definir inclusive a autobiografia, favorita dos estudos literários, quando parece haver-se transformado em outros gêneros ou dissolvido na autoficção? (ARFUCH, 2009, p. 113)

Para a presente análise, essa abertura torna-se fundamental juntamente com a discussão de Lejeune sobre os limites entre o romance autobiográfico e a autobiografia em si - pois procura-se aqui estabelecer tais limites, ou pelo contrário, dissolvê-los a partir de textos que se localizam nesta linha tênue que divide os dois gêneros. Segundo a autora, sua "proposta é justamente ir além dos gêneros auto/biográficos canônicos para abranger a multiplicidade de formas, que atualmente adota a narrativa vivencial, com uma grande diversidade retórica em relação a seus ancestrais do século XVIII [...]" (ARFUCH, 2009, p. 113). Assim, ela retoma as noções de Bakthin, em sua concepção dos gêneros discursivos. Bakthin seria o primeiro a "pensar 
justamente os conceitos de relatividade e de espaço-temporalidade em relação aos discursos sociais e com a literatura em particular." (2009, p. 115). Tendo em vista tal reflexão é possível integrar o romance, ou o romance autobiográfico em uma posição mais próxima à autobiografia, mesmo este sendo composto de elementos ficcionalizantes. Retornando a Lejeune, a experiência do leitor com o texto produz imediatamente o pacto, que define 0 gênero, quando é possível uma interpretação ambígua das relações entre o autor, o narrador-protagonista e o leitor. Segundo Bakthin,

[...] os gêneros são conjuntos constitutivamente heterogêneos, em constante hibridismo, que compartilham certas características e sistemas de valoração, mas cuja especificidade é até relativa; reconhecíveis por sua tradição, porém também sujeitos à mudança histórica ou cotidiana, e especialmente ao movimento sem pausa da interdiscursividade. [...] Dito de outro modo, um espaço biográfico aberto à multiplicidade, onde cada presente da atualidade - do relato - desenha-se sobre o pano de fundo das genealogias narrativas, sobre a temporalidade da própria vida, das vidas dos outros, da vida em geral. ${ }^{8}$

Para Paul de Man, endossando o ponto de vista de Arfuch, a construção de uma narrativa autorreflexiva não depende de uma definição precisa de gênero. Tal construção ocorre no instante da leitura, o eu-lírico, seja testemunhal ou fictício, se encontra no enlace dos personagens constituintes da narração, na identidade, de um narrador e o personagem central, ou no encontro do autor com o personagem, sendo este o reflexo daquele.

Nos estudos dos anos a partir de 1950, Martini analisa O tambor de Günter Grass, o considera um romance histórico e ainda, uma paródia do chamado Romance de Formação, como nos moldes goethianos (SELBMANN, 1994, p. 29). Pode-se, com isso, perceber a transformação do gênero no século XX. Já nos anos 1960 e 1970, devido à tendência do romances a esta época, surge um grande interesse pela biografia ou nova subjetividade sem

\footnotetext{
${ }^{8}$ Arfuch: remeto neste ponto à conhecida análise do termo vivência de Gadamer (1977, pp. 96-107), que retoma a genealogia alemã de Erlebnis em suas vertentes ligadas à escritura autobiográfica, como o caso [mencionado anteriormente] emblemático de Goethe. (ARFUCH, 2009, p. 115)
} 
que logo houvesse a necessidade de inferir-se os avanços no sentido de se legitimar o gênero (SELBMANN, 1994, p. 29; Tradução minha).

\section{Confissões de uma Bela Alma - Goethe}

Partindo da análise que coloca o romance de formação alemão, e sobretudo Goethe - como reforça Arfuch - dentro do gênero romance autobiográfico, é possível perceber elementos no texto Goethiano "As confissões de uma Bela Alma" que delimitariam sua caracterização como uma biografia. Contudo, ao se apropriar dos escritos e cartas de Susanna von Klettenberg, ele traz elementos ficcionalizantes para a narrativa e, ao mesmo tempo, outros, que lhe possibilitam um pacto de leitura que se aproximaria de uma definição de autobiografia, como, por exemplo, ao descrever o processo de formação de uma mulher do século XVIII, o faz se utilizando de uma narração em primeira pessoa.

Em "Historische Bestimmungen. Von Blanckenburg bis Hegel" [Definições históricas. De Blackenburg a Hegel], Rolf Selbmann introduz as acepções que, segundo seu entendimento, constituem a fortuna teórica do Romance de Formação. Ao mencionar o autor Friedrich von Blackenburg, ele explica que, mesmo não definindo exatamente o gênero, este autor lança as bases para a construção conceitual do mesmo. Em um dos pontos, tocante à presente análise, Blackenburg propõe que "o herói deve formar a percepção do leitor"9. Alinhado a esta ideia, Gotthart Heidegger afirma que "não apenas o herói, mas também o leitor deve ser formado" ${ }^{10}$. Segundo Selbmann, tais definições implicam em um autor-narrador previamente formado e que deixa a história de sua formação influenciar como intenção narrativa (SELBMANN, 1994, pp. 8-9). Essa influência sugere o caráter autobiográfico, mesmo antes

\footnotetext{
${ }^{9}$ BLANCKENBURG, 1965, p. 435 apud SELBMANN, 1994, p. 8.

${ }^{10}$ HEIDEGGER, 1698. apud SELBMANN, 1994, p. 8; Tradução minha.
} 
da constituição do Romance de Formação, e que teria possibilitado sua conceituação mais precisa posteriormente.

No texto sobre a Bela Alma, de Goethe ${ }^{11}$, inscrito no livro Weibliches Werden. Sozialisation und Selbstfindung der Frauengestalten in Goethes Wilhelm Meistes Lehrjahre, a autora Daniela Tannenbaum trabalha com a ideia de que o texto se trata de uma autobiografia:

[...] um manuscrito, no qual ela esclarece, como ela se transformou em uma bela alma. Esta autobiografia desempenha um papel especial no romance: se vale de todo o sexto livro, apenas o qual possui um título próprio, Bekenntnisse einer schöne Seele (728). Aqui está a especificidade desta personagem: no relato autobiográfico de seu amadurecimento. (TANNENBAUM, 2009, p. 59). O conceito "Bekenntnisse" [confissões] já implica a tentativa de interpretar e escrever uma história prévia; elas [confissões] vivem no limite entre a consciência presente e passada. ${ }^{12}$

Ao descrever a escrita de Tolstói, em seu texto "Testemunho. Verdade e literatura", Tununa Mercado lembra as caraterísticas do texto do autor, que outrora fora encantado pelo que Mercado define como proveniente do "autor médium", que seria aquele, onde sua palavra poderia ser lida em sua escrita. Segundo ela, a partir dessa palavra mediúnica não se pode antever o autor:

É tamanho o extravio que precede a escrita que quem a executa sequer percebe que escolheu uma pessoa por acaso: abre e o eu se impõe, porque todo enunciador é, primeiramente um eu que pede um você e escapa por um ele; pode permanecer ali, mas por cortesia permite que se passe a terceira pessoa, ou com audácia experimenta o "você". (MERCADO, 2009, p. 33)

\footnotetext{
${ }^{11}$ Capítulo intitulado "Die schöne Seele". Daniela Tannenbaum, em seu livro, analisa as personagens femininas centrais do romance Wilhelm Meisters Lehrjahre, de Goethe e suas contribuições para a narrativa.

12 ZANTOP, Susanne. Eignes Selbst und fremde Formen: Goethes 'Bekenntnisse einer schönen Seele'. Goethe Yearbook 2 (1986), p. 76 apud TANNENBAUM, 2009, p. 59; Tradução minha. Grifo meu.
} 
Assim, Goethe escreve seu "Confissões de uma Bela Alma". O eu de seu texto seria, conforme a explicação de Mercado, retirado do texto - por pertencer a outra pessoa - dando um lugar ao "você". Contudo, Goethe não o faz desse modo. Ele se apropria desse eu, fazendo dele uma confluência entre o fictício, dado pela categorização "romance" e pelos elementos ficcionalizantes impostos pelo autor, e seu correspondente real, dado pelo relato, nas cartas e escritos de Susana von Klettenberg.

Goethe assume o papel de "autor-narrador", nas palavras de Tannenbaum, instituindo uma incongruência entre definições próprias de um relato e, sobretudo, entre seu texto e as categorias autobiográficas propostas por Lejeune. Esse relato ocorre por outra instância, através da intermediação das cartas e escritos da amiga e prima do autor. Contudo, mesmo que isso encerre sua caracterização como tal, ao ser transmitido por uma segunda pessoa, Goethe, e tendo este inserido um conteúdo ficcional, o pacto do autor junto ao leitor é modificado, pois o texto traz consigo elementos de uma ficção, mas sua fundamentação parte de um relato factual. Em outros momentos do seu Wilhelm Meisters Lehrjahre, Goethe se utiliza de outro recurso, que caracteriza um possível pacto autobiográfico, como no momento em que descreve as impressões do próprio Wilhelm, ao ter contato com as "confissões":

O que mais me [Wilhelm] impressionou foi, nestes escritos, gostaria de assim dizer, a pureza do ser, não por somente por si mesmo, mas sim, por tudo que o circunda. Esta autonomia da sua natureza e a impossibilidade de manter consigo, algo que não esteja em harmonia com um temperamento nobre e amável. ${ }^{13}$

Aqui, o recurso utilizado por Goethe, que define o Wilhelm Meisters Lehrjahre como um romance autobiográfico, é justamente o uso da primeira pessoa pelo narrador. A identidade narrador-leitor, proposta por Lejeune, é

${ }^{13}$ GOETHE, pp. 897-898 apud TANNENBAUM, 2009, p. 60. 
confirmada, tal qual o comentário de Leonor Arfuch, considerando Goethe como "autor emblemático" da autobiografia no século XVIII.

A apreensão do conteúdo das "Confissões de uma Bela Alma" por Meister vai de encontro com as premissas supracitadas de Blanckenburg ${ }^{14}$, as quais preveem a formação não somente do autor, mas também do leitor. Para tanto, deve-se reconhecer o texto Goethiano como uma obra autobiográfica - a partir das análises tanto de Arfuch, quanto dos indícios, como o uso da narrativa em primeira pessoa - e os escritos de Susanna von Klettenberg, que seriam um dado que confirmaria sua própria influência para a escrita do romance.

\section{Conclusão}

O Romance de Formação possui elementos que o posicionam em um espaço que coincide com algumas categorias da autobiografia. Segundo autores como Blanckenburg e Morgensten, sua escrita narra não apenas a formação do autor-narrador, mas também possibilita a formação do seu leitor. Tais características aproximam as obras do gênero à autobiografia, pois, segundo Morgenstern, a formação do autor influencia suas intenções de narração.

Philippe Lejeune, no texto "Pacto autobiográfico", defende a impossibilidade de uma obra com elementos ficcionalizantes - como o gênero do romance, grosso modo - ser considerada uma autobiografia. Contudo, em sua teoria ele concorda que para, em última instância, a existência de uma definição da obra como autobiografia, ou ficção, deve-se apresentar um pacto de leitura entre o autor e o leitor. Para tanto, ele define algumas características que determinariam a autobiografia, como a narração em primeira pessoa, ou

\footnotetext{
${ }^{14}$ Karl Morgenstern estabeleceria, posteriormente, as diferenças entre o Romance de Desenvolvimento e o Romance de Formação. Segundo ele, deveria ser chamado Bildungsroman, primeiramente e principalmente devido ao seu conteúdo, por apresentar a formação do herói desde o seu início e desenvolvimento até um determinado nível de plenitude; segundo, porque ele possibilita em um grau mais elevado do que qualquer tipo de romance, essa apresentação da formação do leitor. (MORGENSTERN, [ebd. 13] apud SELBMANN, 1994, p. 11; Tradução minha.
} 
ainda a narração em terceira pessoa, em menção a um personagem que pertença à identidade narrador-personagem principal.

Em "Confissões de uma Bela Alma", Goethe aproxima-se das características que definiriam seu texto como um romance autobiográfico. Ao se apropriar dos escritos e cartas da amiga e prima de sua mãe, Susanna von Klettenberg, ele traz para a narrativa o relato desta, que revelam sua formação, a de uma mulher do século XVIII. O autor também escreve a narrativa em primeira pessoa, fazendo com que a personagem principal possua a identidade proposta por Lejeune.

Para a autora Leonor Arfuch, o Romance de Formação do século XVIII e, sobretudo, Goethe, apresentam características que os inserem na definição de obra autobiografia, expandida por ela, a partir do texto de Lejeune. Ao citar Bakthin, quando este afirma que gêneros literários sofrem mudanças entre si e ao longo do tempo, ela questiona a rigidez de Lejeune, diante das múltiplas interpretações do eu autobiográfico contemporâneo. Ainda, para Gide, o romance contém mais "verdade" do que a autobiografia. O autor Gérard Genette defende não somente uma escrita em primeira pessoa para a autobiografia, mas também aquela que ele denomina de homodiegética, em que a narração é feita em terceira pessoa, remetendo ao personagem central. Tal definição, claramente não se aplica ao texto Goethiano sobre a Bela Alma, mas certamente eles são convergentes entre si, pois Goethe se vale de uma voz feminina, e a partir dos relatos autobiográficos desta, - se valendo de algumas caracterizações propostas por Lejeune como, por exemplo, o pacto a ser estabelecido entre auto e leitor - constrói uma narrativa sobre sua vida e formação. 


\section{REFERÊNCIAS}

ARFUCH, Leonor. "O espaço biográfico na (re)configuração da subjetividade contemporânea". In: GALLE, Helmut et al. (org.). Em primeira pessoa. Abordagens de uma teoria da autobiografia. São Paulo: Annablume; FFLCHUSP. 2009, pp. 113-121.

BENJAMIN, Walter. O narrador. Considerações sobre a obra de Nikolai Leskov. In: Textos escolhidos. São Paulo: Abril Cultural. 1983, pp. 197-221.

GOETHE, Johan Wolfgang von. Os anos de aprendizado de Wilhelm Meister. Trad. Nicolino Simone Neto. São Paulo: Editora 34. 2006.

JACOBS, Jürgen. Vorbereitung des Bildungsromans in deutschen Autobiographien und Romanen des 18. Jahrhunderts. In: . Wilhelm Meister und seine Brüder. Untersuchungen zum deutschen Bildungsroman. München: Wilhelm Flink Verlag. 1972.

LEJEUNE, Philippe. O pacto autobiográfico. In: __. O pacto autobiográfico. Org. Jovita Maria Gerheim Noronha. Belo Horizonte: Editora UFMG. 2014, pp. 15-55.

MERCADO, Tununa. Testemunho. Verdade e literatura. In: GALLE, Helmut et al. (org.). Em primeira pessoa. Abordagens de uma teoria da autobiografia. São Paulo: Annablume; FFLCH-USP. 2009, pp. 31-36.

SELBMANN, Rolf. Historische Bestimmungen. Von Blanckenburg bis Hegel. In: Der deutsche Bildungsroman. Stuttgart: Verlag J.B. Metzler. 1994, pp. 7-14.

. Zur Problematik der Gattung "Bildungsroman". In: Der deutsche Bildungsroman. Stuttgart: Verlag J.B. Metzler. 1994, pp. 27-29.

TANNENBAUM, Daniela. Weibliches Werden. Sozialisation und Selbstfindung der Frauengestalten in Goethes Wilhelm Meisters Lehjahre. Marburg: Tectum Verlarg, 2009. 